
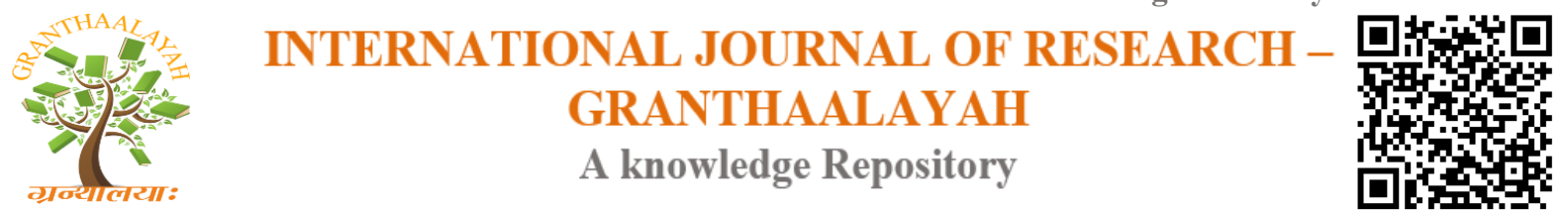

Management

\title{
INVESTIGATING THE ROLE OF KNOWLEDGE MANAGEMENT AS A TOOL FOR ENHANCING INNOVATION AND CREATIVITY IN ORGANIZATIONS
}

Mahboubeh Shateri ${ }^{* 1}$, Roya Safari ${ }^{2}$, Noosha Hozhabrnejad ${ }^{3}$, Hamid Shateri Baghiabadi ${ }^{4}$

${ }^{* 1,3,4}$ M.Sc. graduate, Educational management, Islamic Azad University, Center branch, Tehran, IRAN

${ }^{2}$ M.Sc. graduate, Economic Development and Planning, Alzahra University, Tehran, IRAN

\begin{abstract}
According to modern management literature in the fields of innovation and creativity, it is vital for organizations to innovate to keep up with increasing competition, consumer demands and emerging market fields. Here is where the role of knowledge management is highlighted as a potential key competitive advantage. This paper brings together knowledge from various areas to show that innovation is a form of organizational advantage which can be obtained by appropriate knowledge management. Focus is made the role of knowledge management in sustaining and enhancing creativity in organizations. The simulation of creativity and the allocation of resources for creative thinking methods for employees are also of vital importance. Thus, in the current corporate world, the utilization of knowledge management as a tool for enhancing creativity and innovation will present a competitive edge for organizations.
\end{abstract}

Keywords:

knowledge management, innovation, creativity, competitive advantage, organizations.

Cite This Article: Mahboubeh Shateri, Roya Safari, Noosha Hozhabrnejad, and Hamid Shateri Baghiabadi, "INVESTIGATING THE ROLE OF KNOWLEDGE MANAGEMENT AS A TOOL FOR ENHANCING INNOVATION AND CREATIVITY IN ORGANIZATIONS" International Journal of Research - Granthaalayah, Vol. 4, No. 4 (2016): 82-89.

\section{INTRODUCTION}

In an increasingly volatile business world, innovation has turned into the focal point of most organizations. The speed of innovation has changed the nature of global economic growth via evolving technology, shorter product life spans and the constant development of new products. Corporations must ensure that their business strategies are innovative enough to create and maintain competitive advantage. Creativity has become comprehensive because of changing consumer requirements, extensive competitive pressure and constant technological changes. 
Innovation has also become more complex due to the growth in knowledge available to organizations. According to Stewart (1997), knowledge management and human capital should be an essential element of managing any type of business but only a few individuals comprehend this challenging area; and, given the potential of knowledge management as a source of innovation and renewal, corporate strategies should focus more in these issues. This paper investigates relationships between knowledge management and innovation to increase organizations competitive advantage within their fields of activity.

\section{DEFINITIONS OF KNOWLEDGE MANAGEMENT (KM)}

The focus on issues of power and intellectual capital in the general business and management literature has implications for the study of KM. Where information management was viewed as a somewhat neutral and normative servicing system in the organizational literature in the 1970s (Handy, 1976; McRae, 1971), today KM has emerged as a discrete area in the study of organizations to the extent that it has become recognized as a significant source of competitive advantage (Nonaka, 1991; Nonaka and Takeuchi, 1995; Davis, 1998; Matusik and Hill, 1998; Miller, 1999; Moore and Birkinshaw, 1998; Stewart, 1997). Although having emerged as a field of study in its own right, KM has been criticized for being a misnomer and an oxymoron (Coleman, 1999), or for being "fuzzy" and imprecise (McCune, 1999). While KM has a concrete and tangible side characterized by people, physical systems and processes, there is a great deal of scope for interpretation, as KM practices are highly subjective in nature and subject to various interpretations. There is no shortage of definitions of KM (Liebowitz, 1999); however, for the purposes of this paper we will highlight two broad definitions. For Beckman (1999), KM concerns the formalization of and access to experience, knowledge, and expertise that create new capabilities, enable superior performance, encourage innovation, and enhance customer value. Coleman (1999) defines KM as an umbrella term for a wide variety of interdependent and interlocking functions consisting of: knowledge creation; knowledge valuation and metrics; knowledge mapping and indexing; knowledge transport, storage and distribution; and knowledge sharing.

Knowledge management involves recognizing and identifying the existing intellectual capitals of an organization, generating new knowledge for maintaining the competitive superiority of that organization, providing access to an extensive bulk of information, sharing the best performance using technology which makes it possible to achieve all the mentioned cases.

Knowledge management includes compiling knowledge, rational capacities and experiences of an organization's individuals and developing restoring potential for them as an organizational capital (Perez, 1999). According to Nigel King (1999), knowledge management is the process of developing, organizing, promoting and ensuring an understanding of the necessary information for performing a thing. Newman (1991) believed that knowledge management is a set of processes which involves producing, promoting and applying the subjective and objective knowledge in an organization. In Barclay and Murray viewpoint, knowledge management involves recognizing and identifying the existing intellectual capitals of an organization, generating new knowledge for maintaining the competitive superiority of that organization, providing access to an extensive bulk of information, sharing the best performance using technology which makes it possible to achieve all the mentioned cases. 


\section{KNOWLEDGE MANAGEMENT APPROACHES}

Definitions of the term "knowledge" vary considerably, and often such definitions are not clearly explicated in either the research literature or in the operational context. Information can be characterized as "data endowed with relevance and purpose" (Drucker, 1998), while knowledge can be defined as "information combined with experience, context, interpretation, and reflection" (Davenport et al. 1998). Accordingly, all organizations deal in knowledge. However, organizations can choose between competing systems and processes to acquire, manage, and disseminate knowledge. These systems and processes are explicit as well as implicit and can be influenced by personal and organizational values and ideologies. In terms of an organization's internal systems, organizations actually filter acquired knowledge. For example, one organizational culture may support a devolved structure in KM while another's culture may choose more centralized systems. In another organization, information technology (IT) will drive KM while another organization will favor a more human approach. At various points as knowledge moves through an organization, choices are made about the most appropriate way to manage its flow. Research by Hansen et al. (1999) has indicated that organizations do not adopt a uniform approach to knowledge management. They outline two distinct strategies utilized when selecting a KM approach: a codification strategy, centered on IT resources; and a personalization strategy, centered on human resources (HR).

Indeed, contemporary knowledge management approaches appear to represent extensions of either organizational learning or business information systems, and these KM approaches tend to be driven predominantly within an IT or humanist framework or paradigm, with little if any overlap (Gloet, 2000). This divide between KM approaches has ramifications for both organizational learning and innovation processes. One body of literature on KM has its origins in approaches to IT, information systems and related issues. This canon supports an IT paradigm. In contrast, a competing body of literature supports a humanist paradigm in which the social relations of organizational knowledge are paramount. While this latter paradigm recognizes the technical side of KM, it also highlights the significant influence of people in the process of managing and interpreting knowledge. Whereas literature in the IT paradigm focuses more on tangible aspects of KM, such as collection and manipulation of information, the humanist paradigm concerns itself more with the nature of learning and the harnessing knowledge as an organizational resource. Compared to the "hard" IT paradigm, the "soft" humanist paradigm accords more attention to organizational slogans, metaphors, and symbols (Nonaka, 1991). Consequently, the analysis of $\mathrm{KM}$ in a humanist paradigm is open to more interpretive explanations.

To confound the study of KM in general, the two paradigms necessitate two very different approaches. In the IT paradigm, researchers have accepted various extensions of information processing/business information systems management as springboards into KM. As a consequence, their research focuses on the collection, storage, and manipulation of essentially objective or explicit data, employing methodologies that implicitly construct an organization as an information processing system. This diverts attention to how data are processed, collected, and stored (Lado and Zhang, 1998). Given this implicit focus in the IT paradigm, most KM tools revolve around information systems and software (Fusaro, 1998). 
Within the humanist paradigm, recent literature highlights the role of individuals and groups in the processes of knowledge sharing and manipulation, particularly with regard to highly interpretative forms of knowledge. Other themes in the paradigm include the distinctions between tangible and intangible knowledge, or explicit versus tacit knowledge (Nonaka and Takeuchi, 1995; Nonaka, 1991). In addition, other studies explore the role of knowledge and learning at the systems, organizational, and cultural level of an organization (Nevis et al., 1995). Other literature in the area of KM suggest that a number of organizational or infrastructural elements have the power to influence the success or otherwise of KM within an organization. These include: a healthy organizational culture and support infrastructure (Beckman, 1999; Zand, 1997; Quinn et al., 1997); management support and proactive leadership (Davenport, 1996; Beckman, 1999), empowerment of employees (Davenport and Prusak, 1998; Liebowitz and Beckman, 1998); understanding KM as a business strategy (Ruggles and Holtshouse, 1999); and maintain strong communication channels (Koulopoulos and Frappaolo, 1999).

\section{INNOVATION}

Innovation relates to the total innovation produced by an organization, in terms of the generation and commercialization of ideas for new products, new services, new or improved manufacturing or service delivery processes, and in term of underlying processes (Goffin and Mitchell, 2005). Innovation is context dependent; its exact nature depends on the organization in question. A fundamental approach used in measuring innovation performance is input-output model, where all management processes in organization are viewed as having inputs and outputs. Inputs here refer to the time, investment, people and information technology that go into converting an idea into a product or service that can be sold to customers. Hence applying the input-output model call upon recognition of three measures; input, process and output measures. Input measures such as the revenue invested in research and development, focus on this measure has been criticized by its inability to measure how a firm is turning its R\&D capacity into commercial success (Goffin and Mitchell, 2005). Process measures gauge the efficiency of the innovation process within an organization such as the time it takes to commercialize an innovation. Finally, the output measure relates directly to the commercial impact of innovation (Goffin and Mitchell, 2005). Output measures would include aspects such as revenue generated by the new product, cost saving resulting from the innovation.

Tin (2005) identified various common innovation measures that leading firms were using, some fit within what Goffin and Mitchell (2005) identified above. Darling of most firms as identified by Tin (2005) is revenue or profit growth from new products, this seem to be captured within the output measure. Patent submission was the second measure that is common among firms, this is increasingly becoming a popular approach but one that is misused by businesses as they focus more on the legal side than the business upside. Patent submission critics argue that as a true output measure focus should on the commercialized patents and not just on the mere submission. Another measure proposed by Tin (2005) is idea submission and flow that are captured through idea management system within the firm. This measure can point into the volume and quality of submission within the firm; however, it is more internally focused. Other measures include; gains in market share, time-to-market and conversion rate of patents into products. 


\section{KNOWLEDGE MANAGEMENT AND INNOVATION}

Concurrently with the developments in the field of innovation, there is the hegemony of knowledge management as a key element in improving organizational competitiveness (Hedlund, 1994). Knowledge management includes new knowledge construction, knowledge embodiment, knowledge dissemination and knowledge use/benefit (Demerest, 1997). Quintas et al. (1997) state 'Knowledge management is the process of critically managing knowledge to meet existing needs, to exploit existing knowledge and to develop new opportunities'. These definitions indicate that knowledge management has the potential to be a catalyst for innovation within organizations.

The aim of this paper is to investigate the possible use of knowledge management within organizations as a catalyst or vehicle for increasing innovation, and hence competitiveness. Existing models of KM fall into three broad categories: intellectual capital models (Edvinnson, 1997), knowledge category models (Nonaka and Takeuchi, 1995) and social constructionist models (Demerest, 1997). The model chosen as an example is a modified version of Demerest's model as it is more holistic than the mechanistic intellectual capital models and the reductionist knowledge category models. The model (Figure 1) essentially consists of a highly recursive flow involving four key areas of knowledge.

First, there is the area of knowledge construction where the construction is not limited to that of scientific inputs but includes the social construction of knowledge. Second, the constructed knowledge is embodied within the organization through a process of social interchange. Third, the embodied knowledge is disseminated throughout the organization. Fourth, the use/benefits of KM considers both business and employee emancipator benefits. In effect, as seen in Figure1, there is no specific routing of knowledge around these four key areas, but rather a highly recursive dynamic is produced. The contribution of this view of KM towards the development of innovation is considered as follows, based on the four key areas of the model shown in Figure 1.

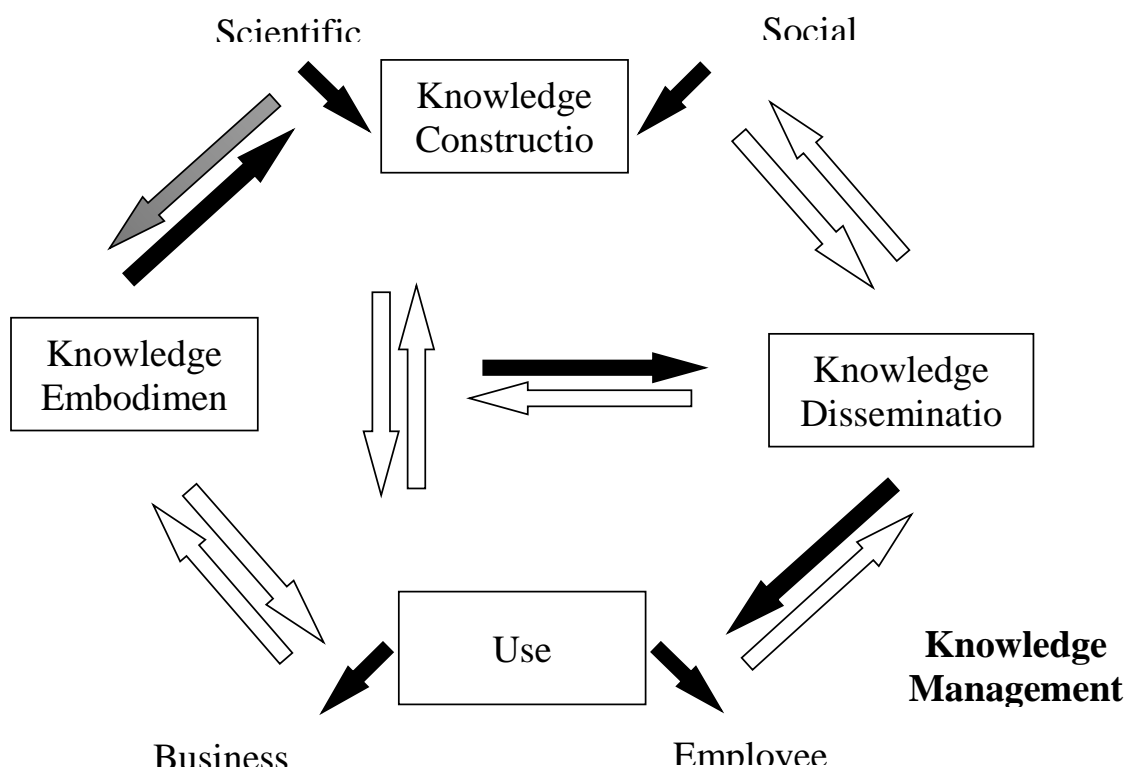

Figure 1: Demerest's Knowledge Management model (modified version) 


\section{CASE STUDY}

Cisco Systems is chosen as an example of the role of innovation in the success of organizations which is attainable by utilizing knowledge management appropriately.

Cisco Systems Inc. is a world-leader in networking solutions for the Internet. Their ability to harness technology has seen them outpace even Microsoft to become the fastest growing, most profitable company in the history of the computer industry (Cisco Systems, 1999). The company has systematically placed innovation at the core of their business, along with a fanatical devotion to customer needs and preferences. At its heart, Cisco is essentially an engine for innovation.

Cisco's operating paradigm has seen them outperform its peers on almost all dimensions of performance since shipping its first product in 1986. The company has averaged 55\% per annum increases in net income between 1995 and 2000 (Cisco Systems, 2000). Cisco's market value per employee at March 2001 was $\$ 3.4$ million relative to their technical peers at $\$ 0.8$ million. Even during the downturn of first-quarter 2001, Cisco's share price was more resilient than its competitors and revenue per employee more than double that of other industry leaders (Häcki \& Lighton, 2001). The strength of Cisco's intangible assets, including their innovation capability, has been recognized by the stock market with a market-to-book ratio of 3.9 times relative to technical-industry peers of 3.6 times.

Cisco recognizes that its core capability is not in manufacturing. In 1992 it determined that suppliers could add more value than Cisco in this area. It has outsourced around $70 \%$ to $80 \%$ percent of everything it sells to a variety of suppliers, including Jabil Circuit Inc. and Automatron Inc (Bunnell, 2000). Cisco integrates this network of suppliers into their organization using knowledge transfer and information technologies, such as intranet and extranet. Cisco was one of the first companies to extend an extranet for communicating with customers, suppliers and partners. Today they have automated their entire manufacturing and shipment process. Furthermore, using such networked applications has enabled their network of suppliers to form what is in effect, a single enterprise. Customer orders flow to the suppliers without the hierarchical systems of parent and subsidiary. By outsourcing most of its manufacturing, Cisco actually pays $30 \%$ less than it would cost to assemble the products inhouse. A continual stream of new products at a low price, high quality and for a mass market is the result. Many of the finished products sold by Cisco never cross a Cisco building threshold.

What remains after all the outsourcing and "virtual organization" concepts are applied is the innovation engine of Cisco Inc. Cisco's strength lies in its ability to scan the environment, identify and then develop profitable sources of new stream ideas and innovations. That is its innovation capability. The result is a company that is profitably growing revenues at 55\% annually, yet is extremely nimble, efficient and innovative. It is not burdened by the considerable investments in technologies and manufacturing plants of its competitors. Cisco can quickly adapt to changing market conditions, product variations and customer needs. Nor is it committed to one dominant technology. The "not invented here" syndrome, so common in many other large firms is minimal. Thus, as new technology develops, the company will purchase, adapt the technology and capabilities, and integrate them with Cisco's own. The company's lack of 
organizational commitment to particular technologies allows it to cannibalize product lines in the search for the next innovation adding significant customer value.

\section{CONCLUSION}

This paper which consists of the gathering of various literature reviews on the role of knowledge management in enhancing innovation within organizations, shows that knowledge management plays a key role in innovation within organizations. Leadership, policies and strategies represent internal affairs and may promote or prevent innovation. Thus, they must present an innovation culture and provide an environment to allow ceaseless and flexible changes to increase organizations' innovative potential. The importance of training and mentoring are paramount in providing employees to be creative. Support through organizational systems and structures are crucial for employees to continually be innovative and acquire new knowledge. Reward systems are even more important than training and mentoring to encourage individuals' innovative performances. Finally, a seamless flow of information and ideas is facilitated via communication which should be enhanced to improve innovation.

\section{FURTHER RESEARCH}

Future research originating from this paper can include the effects of innovation on the acquisition of knowledge. Previous researches are based on causal relationships between knowledge acquirement and innovation but a reverse relationship should also be investigated. Further research may take place to elucidate the relationship between capturing knowledge and innovation. Finally, various types of reward systems could be assessed to highlight which types are more effective in influencing innovation.

\section{REFERENCES}

[1] Barclay RO, Murray PC, 2006. What is Knowledge Management. N Engl J Kmw. 10:4960.

[2] Beckman, T.J. (1999), "The current state of knowledge management”, in Liebowitz, J. (Ed.), Knowledge Management Handbook, CRC Press, Boca Raton, FL.

[3] Bunnell, D. (2000) Making the Cisco Connection - The Story Behind the Real Internet Superpower. New York: America

[4] Coleman, D. (1999), "Groupware: collaboration and knowledge sharing”, in Liebowitz, J. (Ed.), Knowledge Management Handbook, CRC Press, Boca Raton, FL.

[5] Drucker, P. (1985), Innovation and Entrepreneurship, Heinemann, London.

[6] Drucker, P.F. (1998), "The coming of the new organization", Harvard Business Review on Knowledge Management, Harvard Business School Press, Boston, MA.

[7] Gloet, M. and Terziovski, M. (2004), "Exploring the relationship between knowledge management practices and innovation performance”, Journal of Manufacturing Technology Management, Vol. 15, No. 15, pp. 402-409.

[8] Goffin, K. and Mitchell, R. (2005), Innovation Management: Strategy and implementation using the pentathlon framework. 2nd Edition, Palgrave MacMillan, Fith Avenue New York, NY.

[9] Handy, C. (1976), Understanding Organizations, Penguin, Harmondsworth. 
[10] Häcki, R. \& Lighton, J. (2001) the future of the networked company. The McKinsey Quarterly, 3, 26-39

[11] Hedlund G. 1994. A model of knowledge management and the N-form Corporation. Strategic Management Journal 15: $73 \pm 90$.

[12] Hedlund G, Nonaka I. 1993. Models of Knowledge Management in the West and Japan. In Implementing strategic processes, change, learning and cooperation. Lomange, $B$

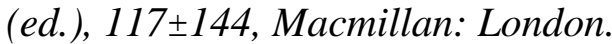

[13] Liao, S., Wu, C., Hu, D., and Tsuei, G. (2009), "Knowledge acquisition, absorptive capacity, and innovation capability: an empirical study of Taiwan "s knowledge-intensive industries", World Academy of Science, Engineering and Technology, Vol 53, Pp160167.

[14] Liebowitz, J. (Ed.) (1999), Knowledge Management Handbook, CRC Press, Boca Raton, $F L$.

[15] Liebowitz, J. and Beckman, T. (1998), Knowledge Organizations: What Every Manager Should Know, St Lucie Press, Boca Raton, FL.

[16] Matusik, S.F. and Hill, C. (1998), "The utilization of contingent work, knowledge creation and competitive advantage”, Academy of Management Review, Vol. 234 October.

[17] McCune, J.C. (1999), "Thirst for knowledge”, Management Review, April.

[18] Miller, W. (1999), "Building the ultimate resource”, Management Review, Vol. 8 No. 2.

[19] Moore, K. and Birkinshaw, J. (1998), "Managing knowledge in global service firms: centers of excellence", Academy of Management Executive, Vol. 12 No. 4 November.

[20] Nonaka, I. (1991), "The knowledge creating company”, Harvard Business Review, November/December.

[21] Nonaka, I. and Takeuchi, H. (1995), The Knowledge Creating Company: How Japanese Companies Create the Dynamics of Innovation, Oxford University Press, New York, NY.

[22] Perez E, 1999. Knowledge Management in the Library not, N Engl J Dm. 2: 75-78.

[23] Quintas P, Lefrere P, Jones G. 1997. Knowledge Management: a Strategic Agenda. Journal of Long Range Planning 30: No. 3, 385 \pm 391.

[24] Stewart, T. (1997), Intellectual Capital: The New Wealth of Organizations, Nicholas Brealey, London. 